\title{
International
}

Journal of Human Studies

Uluslararasi İnsan Çalışmalari Dergisi ISSN: 2636-8641

Cilt/Volume 1 Sayi/Issue 1 Yll/Year: 2018 Gönderim: 14-06-2018-Kabul: 24-06-2018

Old Age, Value and Technology

Yaşl11ık, Değer ve Teknoloji

\section{Seher ÇATALOĞLU*}

\begin{abstract}
Rapidly changing and evolving technology is one of the most important notions of the era. As a result of the technological development, traditional values differentiated and in the modern society old individuals became second class individuals. By time the definition of being old also changed and started to have more social meanings than expressing the body of a person becoming old. In today's world, the people who cannot follow the technology is also considered old. The notion of technology effects the structure of society and gets effected by it too. There's a mutual connection between technology and society which we cannot think apart from each other. Interpreting the technology would require us to consider social, economical, political, cultural and philosophical aspects that shape society. Technology is also
\end{abstract}

Öz

Hızla değişen ve gelişen teknoloji çağın en önemli kavramlarından biridir. Hızlı teknolojik değissimler sonucunda değerler de farklılaşmış modern toplumlarda yaşlı bireyler de ikinci plana koyulmuştur. Zaman içerisinde yaşlılığın tanımı da değişmiş bedenin yaşlanmasını ifade etmekten çok sosyal anlamlar içermeye başlamıştır. Bugün artık teknolojiye ayak uydurmayan da yaşlı olarak görülmektedir. Teknoloji kavramı artık toplumun yapisinı etkilemekte ve ondan etkilenmektedir. Birbirinden bağımsız olarak düşünmediğimiz teknoloji ve toplum arasinda karşllıklı bir etkileşim söz konusudur. Teknolojiyi anlamlandırabilmek için de, toplumu tanımlayan, sosyal, ekonomik, politik, kültürel ve felsefi yönleri de ele almamız gerekmektedir. Gündelik hayatın bir parçası olan teknoloji yaşlı bireyler tarafindan da kullanılmaktadır.

* Seher Çataloğlu, Doktora öğrencisi, Ankara Üniversitesi, Sosyal Bilimler Enstitüsü, Antropoloji Bölümü, sehercataloglu@gmail.com 
being used by elders as a part of daily life. Teknolojik ürünler yaşlı bireylerin hayatına Technological products can contribute positively to the elders daily life but for this to happen, the firms that produces technological products should take elders into consideration as a group of people that are using the technology more and more every day. Feenberg says with a dialectic approach, human needs and purposes can re-shape the technology. Even though the traditional values are being effected by technology, they also lead technological development. If we follow a Feenberg approach, the understanding of being old in modern society that sees being old as an end and a collapsing process should be discussed to be able to re-shape the technology and to ensure individual's demands. The position of the elders in modern societies, the reach of the elders to technology and usage of technology by elders will be discussed in this study. The main argument of the article is producers of technology and society developed an understanding that makes elders feel more old. Elders are thought to be either timid or incompetent to use the technology or not a good market group to buy technology and this understanding causes elders to estrange from technology which is also related to the value systems of modern society. The positions of an elder will tried to be explained in the concepts of directing / guiding / controlling which is one of the meanings of technology. olumlu katk1 sağlayabilmektedir ancak bunun için gündelik hayatta muhtelif teknolojik ürünler üreten firmalar, teknolojiyi üretenler; teknoloji tüketicileri içinde sayısı giderek artan yaşlı nüfusu dikkate almalıdır. Feenberg, diyalektik bir yaklaşımla; insan ihtiyaç ve amaçları, teknolojiyi yeniden biçimlendirebileceğini söyler. Değerler ile teknoloji arasında karşl1ıklı bir etkileşim söz konusudur. Değerler teknolojik gelişimden etkilense bile, teknolojik gelişmeyi yönlendirir (Ural, 2010, s. 1). Feenbergci bir yaklaşımla, teknolojiye yeniden biçim verebilmek, birey taleplerinin etkinliğini sağlayabilmek için modern toplumlardaki yaşlılık algısı, yaşlılığın bir bitiş ve çöküş süreci olarak görülmesi tartışılmalıdır. Bu çalışmada modern toplumlarda yaşlıların konumu, yaşlı bireyin teknolojiye erişimi ve teknolojiyi kullanımı tartışlacaktır. Makalenin argüman, teknolojiyi üretenlerin ve toplumun, yaşlıyı daha yaşlı kılan bir anlayış geliştirdiği, yaşliların teknolojiyi kullanmakta çekingen, beceriksiz ya da iyi bir pazar olmadığı düsturuyla teknolojiden uzaklaştırdıklarını bunun da modern toplumların değerler sistemiyle ilişkili olduğunu iddia etmektedir. Teknolojinin anlamlarından biri olan yönetme/idare etme/kontrol etme bağlamında yaşlı bireyin konumlandırılması yorumlanmaya çalışılacaktır.

Anahtar Kelimeler: Yaşlı, Yaşlilık, Yaşlanma, Teknoloji, Değer, Teknoloji ve Toplum

Keywords: Elder, Old Age, Aging, Technology, $V$ alue, Technology and Society 
Araştırma Makalesi, Doi: https://doi.org/10.35235/uicd.434005

\section{Yaşlılı̆̆ın İnşası}

Yaşlılık nedir? İnsan ne zaman yaşlanır, ne zaman yaşlı olur? İnsanlar artık geçmişte olduğundan daha uzun yaşamaktadır. Modern toplumlardaki yaşlilık deneyimi, yaşam süresinin uzamasıyla beraber önem kazanmıştır. Yaşlanma, yaşlılık, yaşlı gündelik dilde sık sık karşılaştı̆̆ımız kullandığımız ve oldukça da spekülatif kavramlardır. Yaşlanma ve yaşlılık kavramları arasında net bir ayrım yoktur. Genel de bu iki kavram birbirine karıştırılır. "Yaşlanma", "yaşlılık" ve "ihtiyarlık" kavramlarının yanlışlıkla birbirleri yerine kullanıldığı görülmektedir (Duyar, 2008, s. 9). Yaşlılık” sözlük anlamı olarak yaşlı olma, artmış yaşın etkilerini gösterme hali olarak tanımlanmaktadır ${ }^{1}$ ancak; yaşlılık biyolojik süreçler kadar toplumsal ve kültürel süreçleri de kapsamaktadır. Yaşlılık, kısmen bedenin yaşlanmasına dayanırken daha çok sosyal olarak görünür. 'Yaşlılık' ve 'ihtiyarlık' toplumsal bir çevrede, sosyal ilişkiler çevresinde yaşanıp, inşa edilir. Toplumsal ilişki ve yapıların dışında ve ötesinde, soyut ve nesnel bir 'ihtiyarlık/yaşlılık' yoktur (Duyar, 2008, s. 13).

İlkçağda yaşlılık, Tanrı’nın özel kişilere verdiği ayrıcalık olarak nitelendirilmiştir (Canatan, 2008, s. 35-38). Orta Çağ'da yaşlılar hakkında az şey bilinirken Yunan ve Roma Dönemine göre daha kısam yaşam beklentisi olduğu düşünülmektedir. Modernleşmeyle birlikte yaşlılar otoritelerini kaybetmişler (Canatan, 2013, s. 365-367). Modernleşme neticesinde yaşlı gündelik hayatında ve toplumsal konumunda değişiklikler yaşamıştır. Yaşlılığa farklı anlamlar yüklenmiştir. Japonya ve Çin'de yaşlılar bilgelik kaynağı olarak görülürken, Amerika ve Birleşik Krallık’ da bağımlı kişiler, toplumun üstünde bir yük olarak değerlendirmişlerdir (Giddens, 2008, s. 223).

Görece bir kavram olarak yaşlılık, toplumların kendi iç dinamiklerinin, yasam ve geçim biçimlerinin, tarihsel özgüllüklerinin de etkisiyle farklılaşıp çeşitlenmektedir (Duyar, 2008, s. 14). Endüstrileşmeden sonra toplumsal yapıda yaşanan değişimler, göç ve kentleşmeyle birlikte aile yapısının dönüşüme uğraması da yaşlilığın yapısal değişimine neden olmuştur (Ceylan, 2015, s. 35). Gelişmiş toplumlarda, hızlı teknolojik değişimler ve bunun sonucunda farklılaşan değerler, yaşlı insanların sahip olduğu bilgeliği ve yeteneği geçersiz kılmaktadır (Eriksen, 2009). Bu bağlamda modernleşmenin, yaşlanmanın anlamını ve toplumsal ilişkiler içindeki konumunu farklılaştırdığı iddia edilebilir.

Yaşl1lık bireyin demografik özelliklerine göre değişiklik göstermektedir. Niceliksel olarak artan yaşlı nüfusun ve onların çevrelerinin geçirdiği toplumsal dönüşümler ve değişimler, yaşlı bireylerin ve yakınlarının gündelik hayattaki değişimleri, hızlı teknolojik değişmeler bağlamında incelemeyi zorunlu kilmaktadir.

Bireysel farklılıkları göz ardı ettiğimizde, 1972'de Cowgil ve Holmes tarafindan ortaya atılan yaşlanmanın modernleşmesi kuramına göre yaşllların rolleri ve statüleri teknolojik gelişmelerle ters yönde bir ilişkiye sahiptir. Sanayileşme ve teknolojik değişim hızına ayak uyduramayan yaşlı bireyler, teknolojik değişimlerin etkisiyle, deneyim ve birikimlerinin değerini kaybetmektedir. Teknolojik gelişmeler yaşlıların deneyimlerine ve bilgeliğine verilen değerin azalmasına neden olmuştur. Kentleşme ve sosyal hareketlilik aile kurumunu parçalamıştır. Bunun sonucunda yaşlı bireyler, statü ve iktidar kayb1 yaşamaktadırlar (Cowgill, 1986'dan akt., Moody, 2010, s. 8). Modernleşmeyle beraber yaşlı birey toplumsal konumunda ve gündelik hayatında değişiklikler

${ }^{1}$ T. Beğer, H. Yavuzer, Yaşlılık ve Yaşlılık Epidemiyolojisi 
Araştırma Makalesi, Doi: https://doi.org/10.35235/uicd.434005

yaşamıştır. Günümüzde, teknolojik değişimler yaşlılığın farklı bir rol kazanmasına yol açmaktadır. Bu kurama göre, yaşlı bireyler modern toplumlarda daha az değer görmektedirler. Teknolojinin hızına yetişemeyen yaşlı bireylere "modası geçmiş" gözüyle bakılmakta, "Yaşlısın, otur evinde gelinlerin kızların torunların hizmet etsin sana” gibi bir anlayışla yaklaşılmaktadır. Bu anlayış yaşlılı̆̆ın eskime, acizlik ve yardıma muhtaç olmakla eşdeğer olduğu ön kabulünü düşündürmektedir.

Geleneksel toplumlarda bilgileri ve deneyimlerinden faydalanılan yaşlı bireyler toplumsal saygınlıklarını korurken, modern toplumlarda yaşlı bireyin saygınlığı bir nevi tehdit altındadır. Yaşlıların sosyal ve biyolojik bütünlügünü etkileyen bu durum gerontoloji literatüründe geçen ilişki azaltımı kuramı; ileri yaslarda insanların giderek yasamdan, toplumsal ilişkilerden ve günlük aktivitelerden çekildikleri ve bu tür davranmanın da "normal" olduğu düşüncesini ifade etmektedir. ${ }^{2} \mathrm{Bu}$ epistemolojik öncüllerle "yaşlılığı" inşa etme biçimimiz, toplumun teknolojiyi nasıl etkilediği ve teknolojinin toplumsal değerlerden nasıl etkilendiği bağlamında değerlidir. Bireyin belli bir yasa geldiğinde emekli olması, aktif yasamdan çekilmesi, sosyal ilişkilerinin azalması, olması gereken doğal süreçler olarak görülür. Emeklilik yaşı 65’tir ve genel kabule göre, emekli kişi yaşlı bir kişidir. Bir dönem televizyonlarda bankadan maaşını çekmek için beklerken bayılan, kalp krizi geçiren, bankamatiği kullanamayan emekliler bu anlayışın inşasında yer almaktadır. Yaşl1ı̆̆ın değişen anlamı içerisinde, bugün artık teknolojiye ayak uyduramayan da yaşlıdır. Değişen ve gelişen teknoloji ile yaş dilimlerini güncelleyen Dünya Sağlık Örgütü'nün yeni yaş dilimi listesine göre 66- 79 yaş arası orta yaşı ifade ederken, 80-00 yaş arası yaşlı olarak adlandırılıyor. Kronolojik yaşlanmanın sınırlarını belirleyen DSÖ yaşl1lı̆̆1 çevresel etkenlere uyum sağlayabilme yeteneğinin azalması olarak tanımlamaktadır._Batı kültüründe ve bu kültürün etkisinde bulunan toplumlarda yaşl1lı ve ihtiyarlık için kronolojik değerlendirmeler önemlidir. Dünya Sağlık Örgütü (DSÖ) gibi batı kökenli pek çok sosyal ve sağlik kurulusunun anlayış, çalışma ve uygulamalarında bu anlayışı bulabiliriz (Duyar, 2008, s. 14). Hızlı değişme ve farklılaşmaların yaşandığı günümüzde teknolojinin ilerlemesi, nedeniyle toplumsal değerlerin değişmeden kalması ve değişmeden aktarılması neredeyse imkansızdır. Teknolojik gelişmelerin getirdiği değişikliklere uyum sağlamak toplumsal değişmeleri getirir. Teknolojik gelişmeler doğrultusunda yaşlılık değerine yüklenilen anlam modern toplumlarda dönüşmüştür. Modern yaşamın getirdiği hız sonucu yaşlı bireyle geride kalmışır. Bu bağlamda örneğin, her gün televizyonlarda ya da reklamlarda "yaşlanmaya karşı” değerlerle karşılaşmaktayız. Modern toplumlarda, arzu edilmeyen "yaşlılık" olumsuz bir anlama sahip olmuştur. Günümüzde yaşlı bireyler, aile yapısındaki değişiklikler, modernleşme ve ekonomik, teknolojik anlamda gücü ele geçirememeleri sonucu değer kayb1 yaşamaktadırlar ancak; yaşlıların teknolojiye kayıtsız kalmaları mümkün gözükmediği gibi teknoloji üreticilerinin de giderek sayısı artan yaşı bireylere karşı kayıtsız kalmaları olanaklı gözükmemektedir.

\section{Sosyal Değerler ve Teknoloji}

Günümüzde “teknoloji” çağ1 tanımlayan en önemli kavramlardan biridir. Bugün teknolojik çalışmalar uzay, iletişim gibi alanlarda, savaş araçlarının üretiminde dikkat çekmektedir ancak; teknoloji sadece araç ve alet yapmaktan ibaret değildir. Teknoloji kavramı artık toplumun yapısını etkilemekte ve ondan etkilenmektedir. $\mathrm{Bu}$ işleyişin içinde rol almaktadır. Bugün artık teknolojiyi

${ }^{2}$ Hochschild AR: Disengagement Theory: A Critique And Proposaj. Am Sociol Rev 1975; 40:553-569. 
Araştırma Makalesi, Doi: https://doi.org/10.35235/uicd.434005

anlamlandırabilmek için, toplumu tanımlayan, sosyal, ekonomik, politik, kültürel ve felsefi yönleri de ele almamız gerekmektedir.

Feenberg “toplum ve teknoloji birbirinden bağımsız iki ayrı 'şey' değildir”’3 der. Teknolojik gelişmelerin toplumsal yap1, politik süreçler, hukuki ve ekonomik düzen, kurumlar, kültürel birikim ve değerler ile arasında karşılıklı bir etkileşimi vardır. Bireyler yaş aldıkça teknoloji ve yaşamın yapısı ile ilişkileri değişip dönüşmektedir. Teknolojide çok hızlı bir biçimde değişimler ve gelişimler yaşanmaktadır. Artık gündelik hayatın bir parçası olan teknoloji, yaşlı bireyler tarafından sıkça kullanılmaktadır. Yaşı bireyler yaşamını anlamlı kılabilmek ya da kolaylaştırabilmek, sağlı̆̆ını koruyup yaşamını idame ettirebilmek adına teknolojiden faydalanmaktadırlar.

Yaşlıların en temel ihtiyaçları arasında sağlık hizmetleri, kişisel bakım, ev içi ihtiyaçlar, sosyalleşme ve iletişim kurma ihtiyaçları başta gelmektedir. Bunların arasında herhangi bir engel durumundan kaynaklanan ihtiyaçlar da yer almaktadır. Teknoloji, yaşlı bireylerin toplumsal hayata katılımı, bağımlılığı olmadan yaşayabilme, hareket alanı sağlama, güvenlik ve koruma sağlama gibi konularda etkili bir rol oynayıp, fayda sunabilir. Bu durumda yaşlı bireylere yönelik araç, cihaz tasarımı ön plana çıkmaktadır. Yaşlı nüfusun hayli fazla olduğu Japonya'da bir mobil iletişim operatörü (NTTT Docomo), yaşlı bireyler için özel olarak tasarlanmış, klasik akıllı telefonlardan daha geniş ekran menüsüne, daha büyük ve daha kolay okunabilir tuşlara ve klavyeye sahip cep telefonu tasarlamıştır. Japon cep telefonu operatörü, cihazında mesaj gönderme, resim görüntüleme, müzik dinleme gibi tüm komutları yaşlıların erişimine kolaylık sağlaması açısından mümkün olduğunca basitleştirmiştir. Giderek daha yaşlı bir nüfusa sahip olan Japonya'da bu telefonlar ilgiyle karşılanmıştır. Bu bağlamda, yaşlı bireyler için teknolojinin sağlayabileceği kolaylıklar kadar önemli olan bir diğer konu teknolojiyi üretenlerin yaşlı bireyleri göz önünde bulundurması konusudur.

Birey yaşlanmayla beraber görme, duyma ve hareket etme yeteneğinde azalma ve kayıplar yaşamakta, kronik hastalıklarla beraber yetersizlikler çoğalmaktadır. Yaşlı insanlarla konuştuğumda onların hayattan en önemli beklentilerinin "kimseye muhtaç olmadan yaşama", yaşlanmanın neden olduğu kısıtlama ve engellere karşın kendi bağımsız hayatlarını sürdürebilme arzusu olduğunu tekrar öğreniyorum. Kimseye muhtaç olmadan hayatını sürdürebilmek yaşlı bireyler için hayli önemlidir ancak; yaşlı bireylerin bağımlı bir hayat sürdürmemek isterken sağlığını ve güvenliğini tehlikeye düşürecek durumlarda kaldığı, hareket etme yeteneğindeki yetersizliklerin sosyal hayattan uzaklaşmaya hatta soyutlanmaya vardığı gözlemlenebilmektedir.

Çalışmalar, yaşlı bireylerin, teknolojik gelişmelerle oluşturulan ürünler hayatlarını kolaylaştıracak olsa da gençlere nazaran bu ürünü benimseyen en son grup olduklarını ortaya koymaktadır (Özkan, Purutçuoğlu, 2009, s. 38). Feenbeerg, politik ve bürokratik aktörlerin, teknolojiyi oluştururken ve teknolojinin kullanım alanlarında bireylere karşı üstün gücünün, yine bu süreçte diğer aktörlerin edilgenliğinin ve bu süreçler ile sosyal değerler arasındaki uyumsuzluğun teknolojiye karş1 genel bir önyarg1 oluşturduğunu söylemiştir. Bu minvalde, yaşlı bireylerin teknolojik ürünleri kabulde en son grup olduklarına dair iddianın Feenbergci önyargılarla ilintili olduğu ileri sürülebilir. Yaşlı bireye verilen değer, yaşlı bireyin teknolojiyi kullanamayacağına, beceremeyeceğine, akıl edemeyeceğine dair anlayış yeniden tartışılmalıdır. Feenberg'e göre toplumdaki önyarg1 yapı çözümler ile aşılabilir

${ }^{3}$ Feenberg, Heidegger and Marcuse: The Catastrophe and Redemption of History, 2005 
Araştırma Makalesi, Doi: https://doi.org/10.35235/uicd.434005

(Feenberg, 1992). Sosyal değerler teknolojiye entegre edilebilir. Ayrıca Feenberg'e göre, teknoloji nötr bir alan değildir. Bireylerin talepleri gereklidir. Talepler yeni kodlar doğuracaktır ve değerler ahlaksal talep zenginliği yaratacaktır (Feenberg, 2014, s. 706-718). Belli bir yaşın üzerindeki bireylerin teknolojiden korktuğuna ya da kullanmayı istemediğine dair ön kabuller, yaşlı ve teknoloji arasındaki ilişkiye uçurumlar açmaktadır. Yaşı bireylerin teknolojiye karşı ilgisiz olduklanını gösteren bir kesinlik yoktur. Feenberg’in bireyin ihtiyaç ve amaçları doğrultusunda teknolojiyi yeniden biçimlendirebileceğine dair diyalektik yaklaşımı, değerler sorununa göz kırpmaktadır. Modern toplumların, hıza, güce ve yeniliğe önem vermesi dolayısıyla yaşı ilerlemiş bireylerin değersizleşmesi, belki de yaşlı bireylere yönelik yatırımın, karlı olmayan bir yatırım gibi görülmesine dair akıl yürütme, yaşlilar toplumda giderek artan bir nüfusu kaplamasalar bile, ciddi bir sorundur.

\section{Yaşlı Bireyin Teknolojiye Erişimi}

Yaşlı bireylerin sağlıklı ve bağımlı olmayan bir hayata sahip olması önemli bir konudur. Yaşlıların bağımsızlığını engelleyen çeşitli faktörler vardır. Bunlar kronik sağlık sorunları, fizyolojik ve bilişsel bozukluklar, sosyal hayat ve sosyal iletissimden uzaklaşma, giderek azalan hareketlilik ve fiziksel aktivitelerdir. Günümüzde çok hızlı teknolojik gelişmeler yaşamaktayız ve teknoloji birçok alanda olumlu ve işe yarar çözümler getirebilmektedir. Bu bağlamda engeller karşısında teknoloji birtakım çözümler üretebilmektedir. Teknoloji, yaşlılı̆̆ın bağımsızlı̆̆1 engelleyici bazı unsurlarını gidermekte önemli bir rol oynayabilir. Örneğin iletişim teknolojisi araçları yaşlılara uygun bir biçimde tasarlanabilir; ancak yaşlı bireylerin teknolojiyle bağlantıya geçebilmek için sarf ettiği efor daha çok tek taraflıdır. Feenberg'e göre toplumun tüm yaşam alanları gittikçe daha çok tekniğin hükmü altına girmiştir. Bu, koşulsuz kontrol paradigması yaratır. Teknolojinin anlamlarından biri olan yönetme/idare etme/kontrol etme bağlamında baktığımızda teknoloji, ona ayak uyduramayan bireyi, 52 yaşındaki emekli yaşlıyı, banka kartı kullanamadığı için konutta ödemeye yönlendirmiştir. Yaşlı birey teknolojik ürünü kullanamadıkça toplumdan ve sosyal hayattan tecrit ile mi karşılaşmaktadır? ATM'den para çekememek, televizyon ve kablo kumandalarını birbirine karıştırmak, bazı hatların operatörlerinin seslerini duyamayıp talimatlara uyamamak, işitme cihazının sesini ayarlayamamak, toplu taşıma için kontör dolduramamak gibi sayıca çoğaltılabilecek birçok örnek mevcut. Yaşlı bireyler pek çok teknolojik ürünü kullanmakta zorlanmaktadır. Yaşı bireylerin yeni teknolojileri kullanmalarının önünde çeşitli engeller olduğunu söyleyen Paul ve Stegbauer (2005), bu konuda teknik engellerin başta geldiğini iddia etmektedir. Bu engeller arasında, teknolojik ürünler üzerindeki imgelerin ayırt edilememesi, araçların küçüklüğü ya da yaşlıya uygun olmayan dokunmatikliği nedeniyle rahatlıkla kullanılamaması, gözleri zor gören yaşlı bireyin yazı puntolarını okuyamaması, fiziksel engeller nedeniyle toplu taşımaları vs. kullanamaması gibi birçok zorluk sıralanabilir. Ek olarak, yaşlı bireylerin teknolojiyi kullanma konusunda kendilerine güvenmemeleri, alay edilmesi korkusu ve kişisel bilgilerin başkalarının eline geçmesine yönelik mahremiyet zedeleyici olduğu düşünülen bazı psikolojik engeller de olduğunu öne sürmüştür (Abbey ve Hyde, 2009, s. 228). Yaşlı bireyler tasarımı kendilerine uygun olduğu sürece, ihtiyaçlarına göre, teknolojik aletleri kullanmaktadır. Yaşlı insanların teknolojiden korktuğuna ya da kullanmayı istemeyeceklerine dair ön yargının aksine çevremizdeki yaşlı bireylere baktığımızda teknolojinin sadece telefon, bilgisayar ve televizyon ile bile yaşlıların güvenliğini ve bağımsızlı̆̆ını koruduğunu, sosyal ağlar ile iletişimini sağlayıp sürdürmede ne kadar etkili olduğunu 
Araştırma Makalesi, Doi: https://doi.org/10.35235/uicd.434005

gözlemleyebiliyoruz. Önyargılarımızın aksine yaşı bireyler tarafından teknolojik aletler oldukça benimsenmektedir. Televizyon gibi bazı teknolojik aletlerin kullanımı yaşı bireyler tarafından hızla kabul görmüştür. Bakıldığında yaşı bireyler için fayda sağlayan ve kullanım kolaylığı sunulan araçlar kabul görmektedir. Doğrudan yaşlıları hedeflemeyen cep telefonu, dolaylı olarak yaşlı bireylerin hayatına olumlu katkı sağlayabilen teknolojik ürünlerden biri olmuştur. Bugün şalvarının içine mobil telefonu için cep diken babaanne ile yine mobil telefonuna kendi ördüğü k1lıfı kullanan anneanne, bu araçların nasıl benimsendiğine ve yaşlı bireylerin teknolojik araçları kendi hayatlarına nasıl kendi dilleriyle soktuklarının bir göstergesidir. Halbuki bugün Türkiye'de yaşı bireylere yönelik tasarlanmış bir cep telefonu bulabilmek için bile ciddi bir efor sarf etmek gereklidir. Günümüzde mesele, yeni yeni önemsenmeye başlanan yaşlı dostu teknoloji üretiminin canlanmasıdır. Feenberg "Öylece teknoloji diye bir şey yoktur” der. Ona göre günümüzde teknolojiyi sadece bilgi durumumuza göre değil, bilgiyi ve uygulamalarını saptıran iktidar yapılarına göre kullanmaktayız. Çağdaş teknoloji bazı amaçları tercih ederken bazılarını engeller (2010, s. 33).

Feenbeerg'e göre teknoloji pozitivist anlamında "akılcı" değil kültürel ve toplumsal olarak göreceli bir şeydir. Modern toplumlarda teknoloji kendi iç dinamiklerinden etkilenmektedir. Bunlar tasarıma müdahale eden gruplar, teknik uzmanlar, tüzel kişilikler ve hizmet ettikleri siyasal elitler olabilir. Teknoloji, teknik tercihler sonucu belli bir toplumsal gurubun yaşam tarzını destekler. Feenberg bu durumu teknik kod kavramıyla çözümler. Teknik kodlar bize teknoloji sorunsalında problemin sadece teknik olmayacağı, ardında bir çıkar ya da ideoloji ilişkisinin kökleşmiş bulunacağını ileri sürmektedir. Ürünlerin icadının ardında ekonomik ve politik yapılar ve ideolojiler vardır ancak; Feenberg'e göre teknik kodlar aracılardır ve toplumsal dönüşüm kodları da değiştirecektir (Feenberg, 2014, s. 706-718). Bu bağlamda, yaratımında teknik buluşlar kadar, toplumsal süreçlere de bağlı olan teknolojiler, "yaşlı bireylerin teknolojiye karşı uzak olduğu" önyargısından nemalanarak geri planda bırakılmaktadır. Modern toplumların dönüşen yapısında yaşlı bireylerin değersizleşmesi, onlara sosyal, ekonomik ve kültürel olarak gereken önemi vermemeye yol açmaktadır.

Japonya huzurevlerinde yaşı bakımındaki personel açığını çamaşır yıkayan, ortalı̆ı silip süpüren, çay-kahve servisi yapan robotlarla kapatyyor. Haber Japonya'daki tuvalet robotunu müjdeliyor. Bu tuvalet, idrarı anında tahlil ediyor. Tuvaleti kullanan kişinin adını girdikten sonra bir düğmeye basınca, analiz süreci başlıyor. 20 saniye içinde sonuçları tuvalete entegre edilen yazıcıdan alabiliyor; isterse internet üzerinden otomatikman e-maille doktoruna ulaştıriyor. Japon Huzurevlerine Robot" başlklı haber: ${ }^{4}$

"Engelliler için öngördüğümüz bu modeli geliştirirken işlevin yanı sıra tasarıma da büyük önem verdik. Bu tuvalette bir yandan sırtınızı yaslayıp otururken, diğer yandan herhangi bir musluğa dokunmadan ellerinizi yıkayabiliyorsunuz. Her şey, sensör kontrolünde olup bittiğinden daha hijyenik. Musluktan akan suyun rengi, suyun ısısına göre değişiyor; maviden sarıya, suyun hangi sıcaklıkta aktığg LED lambalarla gösteriliyor.”

Japonya'da üretilen yaşlı sayısı hızla artan Almanya'nın da ilgi gösterdiği şefkat robotu Paro'da haberin devamında mevcut. Şubat 2011 tarihli bu habere göz attı̆̆ımızda; yaşlı bireylerin sayısını hızla

${ }^{4}$ http://www.dw.com/tr/japon-huzurevlerine-robot/a-14877406 
Araştırma Makalesi, Doi: https://doi.org/10.35235/uicd.434005

arttığ1 Japonya'da modern toplumlarda yalnız kalan yaşlı bireyin şefkat ihtiyacını karşılamak adına şefkat robotunu üreten Japonya'nın teknoloji aracılığıyla neler yapabileceğinin farkında ve ötesinde olduğu yorumunu çıkarıorum. Ben bugün yaşlı komşuma bu robotlardan bahsettiğimde "ha o tuvalet iyiymiş ama ben makinelerle yaşamam, o ne canım” diye tepki veriyor. Bu durumda, yaşlı bireyi teknoloji hakkında bilgi sahibi etmek, yaşlıya yönelik tasarıma ve kullanıma yönelmek, yaşlı bireyi toplumda dezavantajlı konumdan kurtarmak, teknoloji üreticilerinin "yaşlı dostu” üretime yönelmesi, teknoloji, toplum ve değerler arasındaki bağlantıda örtüktür. Feenberg’in operasyonel bağımsı̨̧lk adını verdiği kavramı, sermaye sahiplerinin ve teknokratların işçilerin ve toplumun ihtiyaçlarını umursamadan teknik karar almadaki özgürlügünün, mevcut ve modern teknolojide belli amaçlar uğruna tercih edilip diğerlerinin engellenip yok sayılmasına neden olduğunu ifade etmektedir. $\mathrm{Bu}$ bağlamda teknoloji ve toplum ilişkisi yeniden yorumlanmasını ve çözüm önerilerinin üretilmesini gerekli bulur. Bu görüşlerini teknolojinin demokratikleşmesiyle ifade eden Feenberg, dışlanan değer ve ihtiyaçlara öncelik vermenin yollarını arayıp toplumsal eleştiriyi salık vermektedir (2010, s. 30-44). Teknolojik gelişimler değerleri etkilediği gibi ondan etkilenirler.

\section{Sonuç Yerine}

Sanayileşme sonrası toplumlardaki değişim hızı yaşl1lı̆̆1 etkilemektedir. Yaşlıların nüfus içindeki artış ise toplumsal değişimi tetiklemektedir. Yaşlılığa bakış açısı toplumdan topluma farklılıklar göstermektedir. Geleneksel toplumlarda yaşlılık ve yaşlılık deneyimlerinin değerli olduğu düşünülürken, sanayileşme sonrası toplumlarda yaşl1lık ve yaşl1lık deneyimlerinin daha az değerli görüldüğü söylenebilir. Modern toplumların dönüşen yapısında yaşlı bireylerin değersizleşmesi, onlara sosyal, ekonomik ve kültürel olarak gereken önemi vermemeye yol açmaktadır. Teknolojiyi üretenler ve toplum, yaşlıyı daha yaşlı kılan bir anlayış geliştirmekte, yaşlıların teknolojiyi kullanmakta çekingen, beceriksiz ya da iyi bir pazar olmadığı düsturuyla teknolojiden uzak tutmaktadırlar ve bu da modern toplumların değerler sistemiyle ilişkilidir. Yaratımında teknik buluşlar kadar, toplumsal süreçlerin de etkin olduğu teknolojiler, yaşlı bireylerin teknolojiye karşı uzaklı̆̆1 önyargısı ile geri planda bırakılmaktadır. Oysa yaşlı bireylerin teknolojiye karşı ilgisiz olduklarına dair bir kesinlik yoktur. Teknoloji ve değer karşl1ıklı olarak birbirini etkiler. Nötr bir alan olmayan teknoloji, bireyin ihtiyaç ve amaçları doğrultusunda yeniden biçimlenebilir. Bugün yaşlı bireylere yeni yeni önem vermeye başlanan teknoloji üretimi canlanmalıdır. Feenbergci bir yaklaşımla, teknolojinin kendi halinde bir şey olmadığı ön kabulüyle, teknolojiyi yalnızca bilgi ve iktidar yapılarına göre kullanmamalıyı. Neticede teknoloji amaçları engellemek ve tercih etmek gibi bir güce sahiptir. Bu bağlamda teknoloji ve toplum ilişkisi yeniden yorumlanmalı ve çözüm önerileri üretilmesi gereklidir.

\section{KAYNAKÇA}

Abbey, R. Ve Hyde, S. (2009). No country for older people? Age and the digital divide, Journal Of Information, Communication\&Ethics in Society, s.228.

Canatan A. (2013). yaşlılar ve toplum- yetişkinlik ve yaşl1lık gelişimi ve psikolojisi. 2.Baskı. İstanbul: Açllım Kitap.

Canatan, A. (2008). Sosyal yönleriyle yaşllık. 1.Baskı. Ankara: Palme Yayınc1lı.

Ceylan, H. (2015). Türkiye'de yaşlilarn yaşam durumları. s. 35. 
Duyar İ. (2008). (R. Mas, A.T. Işık, M.A., T. Karan Beğer, Ş. Akman, T. Ünal; Eds.). In: "Geriatri”, Bölüm 1: Gerontolojinin temelleri. Ankara: TGV; s. 9-19.

Eriksen T. H.(2009). Küçük yerler derin mevzular. 1.Bask1. İstanbul: Avesta Yayınları.

Feenberg A., (1992). From information to communication: The french experience with videotex. In: Lea, M. (Ed.): Contexts Of Computer-Mediated Communication, London: Harvester-Wheatsheaf, S: 168187.

Feenberg A., (2010). Teknoloji ve toplum, ynkacı bir direniş ve yeniden yapılanma. Kalkedon Yayıncilik.

Feenberg A., (2005). Heidegger and Marcuse: The catastrophe and redemption of history. Newyork-London: Routledge.

Giddens A., (2008). Toplumsallaşma, yaşam akışı ve yaşlanma. İstanbul: Kırmızı.

Hochschild AR, (1975) Disengagement theory: A critique and proposaj. Am Sociol Rev ; 40:553-569.

Moody, H. R. (2010). Aging concepts and controversies. California, CA: Pine Forge Press.

Purutçuoğlu. Ö. (2009). Yaşllikta teknolojik yeniliklerin kabulünü etkileyen sosyalizasyon süreci, :38.

Paul, G., ve Stegbauer C., (2005). Is the digital divide between young and elderly people increasing?. First Monday. 10(10). http://Firstmonday.Org/Article/View/1286.

Scharf C. ve Dusek V.(2014). Democratic rationalization: Technology, power and freedom, Andrew Feenberg. s. 706-718.

Ural Ş. (2010). Teknoloji değerler ve havuc. Kalite Kongresi 2, 7-8 Haziran 2001, Abant, Sakarya Kalite Derneği, s.1. 